\title{
MATCHING COMPETITIVE STRATEGY TO PERFORMANCE: AN EXPLORATORY INVESTIGATION IN THE EMERGING ECONOMY OF BAHRAIN ${ }^{1}$
}

\author{
* M. Farid EI SAHN \\ * Ebtihaj AL-A'ALI \\ ** Omneya Mokhtar YACOUT \\ * University of Bahrain, Kingdom of Bahrain \\ ** Alexandria University, Egypt
}

\begin{abstract}
The purpose of this article is to explore the existence of a strategy-performance link in the emerging economy of Bahrain. Cluster analysis is used in an exploratory research design to examine how these practices can be classified according to Porter's generic strategies.A random sample was selected among manufacturing, services, and governmental organizations. The final sample used for analysis was 60 firms. Four clusters related to differentiation, low cost, focused differentiation, and a hybrid strategy were identified. Significant differences were reported among the four clusters with respect to three performance indicators: total assets growth, market share growth, and overall performance.
\end{abstract}

Keywords: Porter's generic strategies, strategic practices, organizational performance.

\section{INTRODUCTION}

The drivers of firm performance and the sources of sustained competitive advantage have been at the core of strategic management research for many years, but with only a limited consensus as to what works best (O'Regan et al., 2011). Porter's (1980) generic strategies provided a framework for examining firms' strategies and how they affect organizational performance. The three generic strategies identified by Porter are low cost, differentiation, and focus. He argues that firms which do not pursue any particular strategy, i.e., "stuck in the middle," will have lower performance than those pursuing low-cost, differentiation, or focus strategies.

Porter's generic strategies have been one of the most studied areas in the field of strategic management. Yet the empirical findings are inconsistent as to their performance implications. Some studies support Porter's assertion that the performance of firms pursuing low-cost and differentiation strategies is superior to that of firms that are stuck in the middle (e.g., Kim \& Lim, 1988; O'Farrell et al., 1993; Powers \& Hahn, 2004). Other studies reported better performance of "hybrids," firms that combine both low-cost and differentiation strategies (e.g., Campbell-Hunt, 2000; Chan \& Wong, 1999; Kim et al., 2004; Leitner \& Guldenberg, 2010; Pertusa-Ortega et al., 2009; Spanos et al., 2004). These inconsistent findings might be attributable to different definitions of stuck-in-the-middle firms, different performance measures used, and the existence of various contingencies that might affect the strategy-performance link.

\footnotetext{
${ }^{1}$ The researchers acknowledge the financial support of the Deanship of the scientific research at university of Bahrain for financing this research.
} 
This research explores the existence of a strategy-performance link in the emerging economy of Bahrain. An emerging economy is characterized by rapid changes (Wright et al., 2005), high uncertainty, and institutional voids, which create serious strategic challenges for both domestic and foreign firms (Hoskisson et al., 2000). Empirical identification of generic strategy types should be extended to different countries, to determine whether these broad approaches to marketing exist widely or instead reflect unique country characteristics or conditions (Dawes \& Sharp, 1996). The Middle East, in particular, has received scant academic research attention as to the existence and impact of generic strategies.

This paper is divided into three sections. The first includes a review of the literature related to Porter's generic strategies and their link with performance. The second section describes the research methodology used. The last section discusses the research findings, academic and managerial implications, limitations, and suggestions for future research.

\section{PORTER'S GENERIC STRATEGIES}

Competitive advantage is critical in order for a firm to perform above average within a given industry. It indicates that a firm is capable of producing value that is seen as superior to that of its competitors. Porter (1980) states that competitive strategy enables a firm to defend itself in a given industry. A strategy, therefore, should be based on a firm's unique and individual advantages, capabilities, and circumstances. Porter asserts that, in order to outperform competitors, a firm must follow one of the strategies that he calls "generic strategies": an overall cost leadership strategy, a differentiation strategy, or a focus strategy.

A company adopting an overall cost leadership strategy seeks to be regarded as the lowest-price producer in a given industry. This happens through the utilization of economies of scale, continuous cost reduction based on experience curve effect, overhead cost control, and seizing cost production opportunities along the firm's value chain. This type of firm will be targeting a broad market segment.

A firm adopting a differentiation strategy will produce products and services that customers view as unique. This type of company addresses many market segments in an industry. Customers are willing to pay a premium price for the added unique values of the products. There are many sources of differentiation a firm can utilize. Developing a unique design or brand image, tailoring and customizing products, creativity, product engineering, customer services, and marketing abilities can all form a foundation for a differentiation strategy.

Finally, a company adopting a focus strategy aims at serving a segment or specific segments of the market. The strategy could represent three types of focus. The first is to focus on low cost in serving the specific market segment or segments. The second is to accommodate the desire of a group of individuals looking for a unique product or products not desired by the majority of customers in the same market. The third is to focus on cost and differentiation to serve a segment or segments in a given market.

Porter states that cost and differentiation strategies are mutually exclusive. A firm can choose to be either an overall low cost provider or a differentiator. If a firm pursues both it will become stuck in the middle and its performance will suffer.

A number of researchers have criticized Porter's framework. Murray (1988) argues that the two strategies of differentiation and low cost are not mutually exclusive. Masokowski (1993) claims that focus strategies by themselves will not produce superior performance. Parnell (2006) believes that a reconceptualization of the Porter-based perspective on competitive strategy is needed. This reconceptualization should reflect the increasing emphasis on both firm resources and the pace and intensity of change in the global business environment, which make speed-response time to competitors and customers-more valuable as a competitive weapon. 


\section{The Strategy -Performance Relationship}

Porter (1980) states that firms should have a clear strategic posture, and that firms characterized as stuck in the middle perform poorly, unlike those pursuing differentiation or low-cost strategies. Empirical evidence has not been consistent as to the effect of different strategies on performance. Some studies supported Porter's theory. For example, Kim \& Lim (1988) examined Porter's four generic strategies in Korea; they report that firms without a clear-cut generic strategy perform less well than those with a generic strategy. O'Farrell et al. (1993) report that firms that are stuck in the middle do not perform as well as those companies adopting a differentiation or focused differentiation strategy. Powers \& Hahn (2004) note that banks considered to be stuck in the middle emphasize only "following the actions of competitors" as a strategic approach, with none of the cost or differentiation competitive methods normally associated with banking success. Only banks that pursued a cost leadership strategy realized a statistically significant performance advantage when compared to the stuck-in-the-middle group, whereas banks that pursued a broad differentiation, customer service differentiation, or focus strategy did not realize a statistically significant performance advantage.

Hybrid strategies were found to be superior to pure strategies in a number of studies. Campbell-Hunt (2000), based on a meta-analysis of the strategy-performance relationship, supports the idea that stuck-in-the-middle strategies may be superior to strategic specialization. Spanos et al. (2004) provide support for the superiority of hybrid over pure forms for competitive advantage in Greek firms. They also confirm that the more generic strategy dimensions that are included in the strategy mix, the more profitable the strategy is, provided that one of the key components is low cost. Chan \& Wong (1999) report that Hong Kong banks adopting a multi-strategic approach outperformed their single-strategy rivals. They also noted that banks can combine apparently incompatible value-creating activities in a synergistic way to achieve integrated flexibility. Kim et al. (2003) find that for firms using click and brick-and-click approaches, integrated strategies that combine elements of cost leadership and differentiation will outperform strategies consisting only of cost leadership or differentiation.

A number of researchers note that "stuck in the middle" may not describe a single type of company. Within the stuck-in-the-middle group, there are companies that deliberately combine traditional lowcost production and differentiation (i.e., follow a hybrid strategy), companies that change their strategy, and companies that have no strategy (Leitner \& Guldenberg, 2010).

Firms pursuing a hybrid strategy have a dual emphasis: they seek both efficiency (low costs) and differentiation. Even Porter (1985) notes that firms pursuing a differentiation strategy should have cost-parity with competitors, and firms having low-cost leadership should also have differentiationparity with competitors. Such parity reflects to a great extent the idea of combined or hybrid strategies. Otherwise, being stuck in the middle would produce no competitive advantage at all, with a high cost position and a low level of differentiation (Pertusa-Ortega et al., 2009). Leitner \& Guldenberg (2010) found that small and medium enterprises (SMEs) that pursue a combination strategy achieve equal or greater financial performance than SMEs with cost-efficiency or differentiation strategies. Firms following a hybrid strategy also outperform companies with no generic strategy in terms of profitability and growth. Pertusa-Ortega et al. (2009) also provide empirical evidence that hybrid strategies are related to higher firm performance levels, regardless of the industrial sector to which they belong. They add that innovation differentiation has become one of the most important dimensions in terms of firm competitiveness. Firms pursuing hybrid strategies may address customer needs better; they may be more difficult to imitate; and they may generate a more flexible, wider view.

Parnell (1997) also notes that "stuck in the middle" includes firms that attempt to combine strategies in a haphazard manner and those that balance low-cost and differentiation strategies. "Balancers" in the study experienced superior profitability while maintaining competitive growth rates.

Dess \& Davies (1984) note that the strategy-performance link depends on the performance indicator used. They used cluster analysis to identify the pattern of intended strategies in a fragmented industry. Companies pursuing a low-cost strategy were the best those sales growth, companies pursuing focus strategies had the highest performance, followed by low-cost, then differentiation, and finally stuckin-the-middle. 


\section{The Strategy -Performance Gap}

There is a gap in the literature concerning strategic practices as they relate to organizational performance (Allen \& Helms, 2006). There are three reasons for this gap. The first reason relates to the perspective used in examining the strategy-performance link. The second reason relates to the existence of a large number of moderators and mediators when studying such a relationship. The third reason relates to the different approaches used in measuring performance.

Perspective. With regard to the perspective used in examining the strategy-performance gap, a number of researchers note that Porter emphasized forces driving industry competition and how they affect performance. Thus, Porter emphasizes one single perspective-the industrial organization theory-in examining firm performance, and ignores the resource-based perspective (O'Regan et al., 2011).The industrial organization perspective has been criticized for its inability to explain large performance variances within a single industry (Parnell, 2006). The company resources and competencies required to implement each strategy effectively also affect performance (O'Farrell et al., 1993; Olson et al., 2005; Walker \& Reukert, 1987). In the same vein, Masokowski (1993) reports that for entrepreneurial firms, certain types of resources and certain types of strategies associated with these resources will lead to superior performance.

Chan \& Wong (1999) note that the positive effect of hybrid strategy depends on a bank's organizing and coordinating capabilities, which are developed and refined through managerial commitment, learning, and experience, as well as a careful assessment of various organizational activities and their interrelationships within the entire business system. In their study of local and foreign firms operating in China, $\mathrm{Li} \& \mathrm{Li}$ (2008) argue that the lack of managerial competencies leads to problems in addressing the conflicting objectives of high quality and low cost at the same time. Supporting this view, Li et al., (2009) argue that, for multinational companies (MNCs) working in China, political ties impede and business ties strengthen the positive effect of a differentiation position on foreign firms' profitability. Finally, Leitner \& Guldenberg (2010) note that the use of modern technologies and management practices, such as quality management and flexible production technologies, allow firms to simultaneously reduce costs and differentiate products. A combination strategy may help to reduce market risk and maximize long-term performance.

A comprehensive understanding of the strategy-performance relationship requires the inclusion of both sets of strategic factors, differentiation and low cost (Parnell, 2006). The concept of strategic groups provide an intermediate frame of reference between viewing the industry as a whole and considering each firm separately (Parnell, 2006; O'Farrell et al., 1993). Parnell (2006) states that strategic groups are composed of businesses in a given industry that seek to execute similar competitive strategies. If strategic groups can be identified, comparisons between their performances can be made to see if a particular strategic approach is superior to the others (Chan \& Wong, 1999).

Moderators and mediators. The second reason for the strategy-performance gap is related to the large number of moderators and mediators in the strategy-performance link. Campbell-Hunt (2000) notes that the failure of the paradigm's theory of performance to provide one universal explanation, based on the presence or absence of specialization in competitive strategies, suggests that contingency theories of performance may now offer more powerful insights into the sources of effective competitive strategy.

The most important moderator identified is the firm's environment. Li \& Li (2008) provide empirical evidence that the effect of generic strategies on financial performance is moderated by the scope of market coverage (whether the firm is domestic or foreign) and by the degree of market concentration, and that MNCs may attain higher performance when using cost-based or dual strategies. Conversely, Baack \& Boggs (2008) report that cost-leadership strategy by developed-country MNCs is rarely effective in emerging markets, and that MNCs may benefit from using different strategies in different markets.

Market concentration is another environmental moderator of the strategy-performance link. Li \& $\mathrm{Li}$ (2008) report that the effect of a differentiation strategy is stronger when the level of market concentration is low rather than high. Parker \& Helms (1992) also argue that cost strategies alone may be insufficient if cost emphasis is the industry norm. 
Amoako-Gyampah \& Acquaah (2008) note that increased competition resulting from economic reforms in Ghana can lead a firm pursuing a cost-leadership or a differentiation strategy to emphasize quality in order to to achieve higher performance. Davis and Walters (2004) examine environment, strategy, and performance among firms in China. Their results indicate that firms in China do not trade off one strategic direction against another, and certain strategy/environment coalignments have significant implications for performance. Parnell (1997) argues that balancers may succeed when buyers demand high value, whereas organizations adopting pure strategies may succeed when buyers are more diverse in their wants and needs. It is also possible that in stable, mature industries, pure defender strategies may yield the highest performance levels.

A number of researchers have examined the effect of organizational variables as shared. functional coordination, with responsibility for key functions unified under the business manager.

Lumpkin \& Dess (2006) examined the moderating role of simplicity on the relationship between strategy and performance measured by market share, profitability, and return on investment. All three of the performance variables were significant for the overall low-cost strategy, and one of the performance variables (market share) was statistically significant for the focus strategy. None of the performance variables were statistically significant for the differentiation strategy. This indicates that performance is higher when simplicity is matched with strategy content that is relatively simpler. That is, a strategy that is focused or directed towards a narrowly construed goal, such as cost cutting or niche marketing, is likely to benefit from simplicity in strategy-making.

Parnell (2010) also reports the moderating role of strategic clarity on the relationship between strategy and performance. He finds that businesses with either low or high strategic clarity outperform those with moderate levels.

Measuring performance. The third reason for the inconsistency in research findings related to the strategy-performance relationship is the difficulty of measuring organizational performance. This difficulty results from having various groups of performance indicators, with each group measuring different aspects. Walker \& Reukert (1987) state that the important performance indicators can be classified into three groups: effectiveness, efficiency, and adaptability. Effectiveness measures reflect the success of a firm's products and programs in relation to those of competitors in the market. It includes sales growth in relation to a competitor and growth in market share. Efficiency measures reflect the outcome of business programs in relation to the resources used to produce them. They include measures such as profitability as a percentage of sales and ROI. Adaptability measures reflect the success of the business over time in responding to changes in the environment. It includes measures such as the percentage of sales from products introduced in the last five years. Empirically, Kumar \& Subramanian (1998) used several different performance indicators when examining the strategy-performance link. They suggest the use of an adaptability measure (new product development) for the differentiation strategy, and an efficiency measure (expense control) for the lowcost strategy.

Allen \& Helms (2006) mention another difficulty in assessing the strategy-performance link. They argue that when a sample contains a variety of industries, performance measurement and comparisons can be particularly problematic. What is considered excellent performance in one industry may be considered poor or middling performance in another industry. If researchers limit themselves to a single industry, the performance measures may be more meaningful, but the findings cannot necessarily be generalized to other industries.

Finally, Park \& Helms (1992) provide empirical support that pure strategies are associated with specific managerial objectives. Growth in sales revenue and employment are associated with differentiation, while financial performance is related to cost containment activities. These findings suggest a need to match generic strategies with the desired goals. When firms combine generic strategies, they are pursuing multiple goals. 


\section{RESEARCH METHODOLOGY}

\section{Population and sampling}

The population of the study is defined as all the medium- and large-sized organizations operating in the Kingdom of Bahrain. The list of these organizations was obtained from the Consulting and Training Centre at the University of Bahrain, which provides such services to a large number of Bahraini organizations. Hoskisson et al. (2000) has observed that obtaining representative samples through conventional sampling techniques may be problematic in emerging economies due to missing, inaccurate, and inconsistent information. The list includes 154 organizations of all kinds, i.e., manufacturing, services, and governmental organizations. The sampling unit is the company, and the sampling element is the manager who manages a certain unit within the organization and has at least six months' work experience with this organization. The use of key informants is justified because these managers have issue-related knowledge and hence the ability to answer the questionnaire.

A simple random sample of 80 organizations was drawn from the list. Sixty-eight responses to the questionnaire were obtained, six of which were eliminated during the verification process for the analysis of data. The final sample was 62 responses, yielding a response rate of $70.5 \%$, which is considered an acceptable rate in this kind of survey.

\section{Measurement of Research Variables}

Three groups of variables were included in the analysis. The first group of variables includes information about the organization and the sector to which it belongs.

The second group of variables includes strategic tactics. The scale used was the one developed by Allen \& Helms (2006) for strategic tactics. The scale included 25 items related to various strategic tactics such as vigorous pursuit of cost reduction, innovation in marketing, and emphasis on advertising. Respondents were asked to estimate how frequently the various strategic practices are used by their organization, on a scale from 0 (never) to 100 (always).

The third group of variables includes performance measures. The difficulty of obtaining objective performance measures and the use of a multi-industry sample is well documented in the literature (Allen \& Helms, 2006; Pertusa-Ortega et al., 2009). The problem is even greater in emerging economies because of the inherent problem of financial reporting that is not based on conventional standards, problems of comparing financial reports over time when different systems are used, inflation, and firms hiding profits to evade taxes (Hoskisson et al., 2000). Therefore, subjective performance measures were used. These measures were growth in total revenues, growth in total assets, net income growth, market share growth, and overall performance (Allen \& Helms, 2006). A five-point scale was used with anchors lowest (1-20\%) and highest (81-100\%), in addition to a "not applicable" point (0).

\section{Factor Analysis and Reliability Tests}

Before the cluster analysis, factor analysis was conducted to examine convergent validity of the research variables. Table 1 shows that the Kaiser-Meyer-Olkin (KMO) measure of sampling adequacy for factor analysis was .682 and Barlett's test of sphericity was 858.921 (significant at .000). These two tests showed that factor analysis could be used to analyze the data.

Table 1. Kmo And Barlett's Test Of Sphericity

\begin{tabular}{|l|l|r|}
\hline \multicolumn{2}{|l|}{ Kaiser-Meyer-Olkin measure of sampling adequacy } & .682 \\
\hline Bartlett's test of sphericity & Approx. chi-square & 858.921 \\
\cline { 2 - 3 } & Df & 253 \\
\cline { 2 - 3 } & Sig. & .000 \\
\hline
\end{tabular}

For the strategic tactics, confirmatory factor analysis was conducted and the 25 competitive method scores were subjected to principal components factor analysis, with four as the number of factors. A varimax rotation was employed to simplify the factor matrix columns and to obtain a well-defined grouping of variables on each factor. The percentage of variance explained by the four factors was 58.772. Allen \& Helms (2006) included the highest factor loadings for each item. They noted that this 
is not to imply that any of the individual strategic practices is exclusive to a single strategy. Similar to their results, training of front-line employees cross-loaded on the three factors, but the highest loading was on factor two. Table 2 shows the results of the factor analysis for strategic tactics and the alpha coefficients for the resulting factors.

Table 2. Factor Analysis And Alpha Coef Ficients For Strategic Tactics

\begin{tabular}{|c|c|c|c|c|}
\hline \multicolumn{5}{|c|}{ Component Matrix } \\
\hline & $\begin{array}{l}\text { Factor } 1 \\
\text { Alpha }=.814\end{array}$ & $\begin{array}{l}\text { Factor } 2 \\
\text { Alpha }=.699\end{array}$ & $\begin{array}{l}\text { Factor } 3 \\
\text { Alpha } \\
=.89\end{array}$ & $\begin{array}{l}\text { Factor } 4 \\
\text { Alpha }=.46\end{array}$ \\
\hline Vigorous pursuit of cost reductions & & & .939 & \\
\hline Tight control of overhead costs & & $\begin{array}{c}-.709 \\
\text { Deleted }\end{array}$ & & \\
\hline Providing outstanding customer service & & -.536 & & \\
\hline Improving operational efficiency & & & .939 & \\
\hline Controlling the quality of products/services & & & .756 & \\
\hline Extensive training of front-line personnel & .503 & & & \\
\hline Intense supervision of front-line personnel & & .716 & & \\
\hline Extensive training of marketing personnel & & .581 & & \\
\hline $\begin{array}{l}\text { Maintaining high inventory levels (for } \\
\text { manufacturing organizations) or high staffing } \\
\text { levels (for non-manufacturing organizations) }\end{array}$ & & .596 & & \\
\hline Competitive pricing & & .502 & & \\
\hline $\begin{array}{l}\text { Developing a broad range of new } \\
\text { products/services }\end{array}$ & .678 & & & \\
\hline Refining existing products/services & & .504 & & \\
\hline $\begin{array}{l}\text { Developing brand or company name } \\
\text { identification }\end{array}$ & & & & .465 \\
\hline $\begin{array}{l}\text { Innovation in marketing techniques and } \\
\text { methods }\end{array}$ & .732 & & & \\
\hline Providing specialty products/services & .766 & & & \\
\hline $\begin{array}{l}\text { Producing products/services for high-price } \\
\text { market segments }\end{array}$ & .827 & & & \\
\hline Utilizing advertising & .693 & & & \\
\hline $\begin{array}{l}\text { Building a positive reputation within the } \\
\text { industry for technological leadership }\end{array}$ & .619 & & & \\
\hline Forecasting existing market growth & .467 & & & \\
\hline Fostering innovation and creativity & .604 & & & \\
\hline Partnering with suppliers & .520 & & & \\
\hline $\begin{array}{l}\text { Minimizing distribution costs (for } \\
\text { manufacturing organizations) or service costs } \\
\text { (for non-manufacturing organizations) }\end{array}$ & & .727 & & \\
\hline Dropping unprofitable customers & & .668 & & \\
\hline Building market share & & .557 & & \\
\hline Target niche & & & & .806 \\
\hline
\end{tabular}

Based on the results of the factor analysis, four factors were obtained. The first factor includes the items reflecting extensive training of front-line employees, developing a broad range of products, innovation in marketing techniques and methods, providing specialty products and services, producing products/services for high-price market segments, utilizing advertising, building a positive reputation within the industry for technological leadership, forecasting existing market growth, fostering innovation and creativity, and partnering with suppliers. This factor was named "differentiation." Alpha coefficient for this factor was .814.

The second factor includes items related to tight control of overhead cost, providing outstanding customer service, intense supervision of front-line employees, extensive training of marketing personnel, maintaining high inventory levels (for manufacturing organizations) or high staffing levels (for non-manufacturing organizations), competitive pricing, refining existing products, minimizing distribution costs (for manufacturing organizations) or service costs (for non-manufacturing 
organizations), dropping unprofitable customers, and building market share. Alpha coefficient for this factor was .18, but when the overhead was eliminated, alpha coefficient reached .70. This factor was named "hybrid strategy."

The third factor included items related to vigorous pursuit of cost reduction, improving operational efficiency, and controlling the quality of products and services. This factor was named "low cost." Alpha coefficient for this factor was .89.

The fourth factor included two items related to developing brand or company name identification and targeting a market niche. This factor was named "focused differentiation." Alpha coefficient for this factor was .46. This factor was thus eliminated from further analysis.

Based on these findings, the three variables of "differentiation," "low-cost," and "hybrid" strategies will constitute the cluster variate in the cluster analysis.

\section{The Use of Cluster Analysis}

Cluster analysis is an exploratory data analysis tool for organizing observed data (e.g., people, things, events, brands, companies) into meaningful taxonomies, groups, or clusters, based on combinations of variables, which maximizes the similarity of cases within each cluster while maximizing the dissimilarity between groups that are initially unknown (Burns \& Burns, 2008).

A number of researchers have stated that respondents can be classified into a number of distinct strategic groups based on the strategies they employ (e.g., Dess \& Davis, 1984; Kim \& Lim, 1988). Chan \& Wong (1999) argue that cluster analysis can be used to identify strategic groups; comparisons between their performances can then be made to see if a particular strategic approach is superior to the others. O'Regan et al. (2011) note that cluster analysis has been a preferred methodology for many strategy-performance studies, especially exploratory investigations at the strategic group level of analysis. The primary weakness of cluster analysis is that it concentrates on similarities within clusters (groups) and does not account for strategy differences within groups.

The six-stage model-building approach recommended by Hair et al. (1998) was used.

Defining the problem. The first stage includes defining the research problem, the research objectives, and the cluster variate. The cluster variate is the set of variables representing the characteristics used to compare objects in the cluster analysis. The cluster variate in this research will include differentiation and hybrid strategic tactics.

Research design. The second stage in cluster analysis is the research design. This step includes decisions related to detection of outliers, determining whether data should be standardized, and determining how similarity should be measured.

With respect to outliers, two types of analysis will be undertaken, one for detecting univariate outliers and the other for detecting multivariate outliers (University of Texas) .One way to identify univariate outliers is to convert all of the scores for a variable to standard scores. If the sample size is small (80 or fewer cases), a case is an outlier if its standard score is \pm 2.5 or beyond. Only two outliers were detected for the differentiation variable and hybrid; they were deleted from the analysis.

The Mahalanobis test of distance was used to detect multivariate outliers. The Mahalanobis $\mathrm{D}^{2}$ evaluates the position of each observation compared with the center of all observations on a set of variables (Hair et al., 1998, p. 67). The significance levels for $\mathrm{D}^{2}$ were calculated and sorted ascendingly. Cases with significance levels less than .001 are considered outliers. Two cases were eliminated as outliers. Thus, the final sample size is 60 .

With respect to standardizing the variables, non-standardized coefficients were used since the three variables in the cluster variate were measured using the same 7-point scale. For measuring similarity, distance measures of similarity represent similarity as the proximity of observations to one another across the variables in the cluster variate (Hair et al., 1998, p. 484). The squared Euclidean distance will be used. The Euclidean distance is the length of the hypotenuse of a right triangle.

Determining the assumptions. The third stage in the cluster analysis is to determine the assumptions of the analysis. These assumptions are identified by Hair et al. (1998) as sample representativeness and 
absence of multicollinearity. The sample used in this research is a simple random sample, which means that the first assumption (representativeness) is valid. To examine multicollinearity among variables included in the cluster variate, Myers et al. (2006) recommend the use of variance inflation factors (VIF). VIF measures the degree of linear association between a particular independent variable and the remaining independent variables in the analysis. As shown in table 3, the VIFs of the three variables included in the cluster variate were less than 10, indicating absence of multicollinearity (Norusis, 1990).

Table 3. Tests Of Multicollinearity

\begin{tabular}{|l|r|r|}
\hline \multirow{2}{*}{ Model } & \multicolumn{2}{|l|}{ Collinearity statistics } \\
\cline { 2 - 3 } Tolerance & VIF \\
\hline Low-cost & .877 & 1.140 \\
\hline Hybrid & .434 & 2.306 \\
\hline Differentiation & .451 & 2.217 \\
\hline
\end{tabular}

Deriving clusters. The fourth stage involves deriving clusters and assessing overall fit. In this stage the clustering algorithm is selected. This algorithm refers to the set of rules used in clustering (Hair et al., 1998). For such a small sample size, the hierarchical cluster analysis is recommended (Norusis, 1990). It starts with each case as a separate cluster - there are as many clusters as cases — and then combines the clusters sequentially, reducing the number of clusters at each step until only one cluster is left (Burns \& Burns, 2008). Ward's method will be used, since it measures the distance between two clusters as the sum of squares between the two clusters summed over all variables (Hair et al., 1998).

To determine how many clusters should be formed, Hair et al. (1998) state that it is best to compute a number of different cluster solutions and then decide among the alternative solutions by using a priori criteria, practical judgment, common sense, and theoretical foundations. Based on Dess \& Davies (1984) and Allen \& Helms (2006), a four-cluster solution was selected to reflect clusters related to differentiation, low-cost, and hybrid strategies.

Interpreting the clusters. Stage five is the interpretation of the clusters. This entails labeling the clusters and describing their profiles. Descriptive statistics were used to examine the four clusters. Table 4 presents descriptive statistics and results of one-way analysis of variance. The table shows that the four clusters vary significantly with respect to the variables included in the cluster variate.

Cluster 1 consisted of 22 companies and had the highest score for differentiation and hybrid strategies. The low-cost strategy score was lower than that of cluster 3 . This cluster was named "differentiators."

Cluster 3 consisted of nine companies. It had the highest score with respect to low-cost strategy ( $\mathrm{F}<$ .000). The scores of differentiation and hybrid strategies were slightly lower than that of cluster 1 but were higher than the same scores obtained from clusters 2 and 4.This cluster was called "low-cost providers." Clusters $2(n=17)$ and $4(n=12)$ represented hybrid strategies but with different strategic postures. While cluster 4 had higher scores than cluster 2 with respect to differentiation and hybrid strategies, both clusters had almost the same scores with respect to low-cost strategy. Cluster 4 was thus named "hybrids," and cluster 2 was called "stuck in the middle."

Validation. Stage six is the validation of the cluster solutions. Burns \& Burns (2008) recommend the use of ANOVA to validate the differences. One-way ANOVA was used to examine differences among the means of the four clusters with respect to the five performance indicators. Significant differences were obtained for three performance indicators: total assets growth, market share growth, and overall performance. For total assets growth, hybrids had the highest mean, followed by low-cost providers, differentiators, and finally stuck-in-the-middle $(\mathrm{F}<.001)$. For market share growth, lowcost providers had the highest mean, followed by differentiators, hybrids, and stuck-in-the-middle ( $\mathrm{F}$ $<.00)$. For overall performance, differentiators had the highest mean, followed by low-cost providers, hybrids, and stuck-in-the-middle $(\mathrm{F}<.000)$. No significant differences were obtained among the means of the four clusters for net income growth and total revenue growth. 
Table 4. Descriptive Statistics And Results Of One-Way Anova

\begin{tabular}{|c|c|c|c|c|c|c|c|c|c|c|}
\hline & & $\begin{array}{l}\text { Sum of } \\
\text { squares }\end{array}$ & df & $\begin{array}{l}\text { Mean } \\
\text { square }\end{array}$ & $\mathrm{F}$ & Sig. & \begin{tabular}{|l|} 
Cluster 1 \\
$\mathrm{n}=22$ \\
Differentiation
\end{tabular} & \begin{tabular}{|l|} 
Cluster 2 \\
$\mathrm{n}=17$ \\
Stuck in the \\
middle
\end{tabular} & $\begin{array}{l}\text { Cluster } 3 \\
n=9 \\
\text { Low-cost }\end{array}$ & $\begin{array}{l}\text { Cluster } 4 \\
n=12 \\
\text { Hybrid }\end{array}$ \\
\hline \multirow{3}{*}{$\begin{array}{l}\text { Differentia } \\
\text { tion }\end{array}$} & $\begin{array}{l}\text { Between } \\
\text { groups }\end{array}$ & 25.871 & 3 & 8.624 & 27.290 & .000 & 5.47 & 3.96 & 5.42 & 4.55 \\
\hline & Within groups & 17.696 & 56 & .316 & & & & & & \\
\hline & Total & 43.568 & 59 & & & & & & & \\
\hline \multirow{3}{*}{ Hybrid } & $\begin{array}{l}\text { Between } \\
\text { groups }\end{array}$ & 7.018 & 3 & 2.339 & 8.857 & .000 & 5.47 & 3.96 & 5.42 & 4.55 \\
\hline & Within groups & 14.791 & 56 & .264 & & & & & & \\
\hline & Total & 21.809 & 59 & & & & & & & \\
\hline \multirow{3}{*}{ Low-cost } & $\begin{array}{l}\text { Between } \\
\text { groups }\end{array}$ & 41.001 & 3 & 13.667 & 41.258 & .000 & 4.37 & 3.96 & 4.93 & 3.95 \\
\hline & Within groups & 18.551 & 56 & .331 & & & & & & \\
\hline & Total & 59.551 & 59 & & & & & & & \\
\hline \multirow{3}{*}{$\begin{array}{l}\text { Total } \\
\text { assets } \\
\text { growth }\end{array}$} & $\begin{array}{l}\text { Between } \\
\text { groups }\end{array}$ & 31.480 & 3 & 10.493 & 6.437 & .001 & 2.44 & 3.2 & 4.04 & 4.58 \\
\hline & Within groups & 91.285 & 56 & 1.630 & & & & & & \\
\hline & Total & 122.765 & 59 & & & & & & & \\
\hline \multirow{3}{*}{$\begin{array}{l}\text { Net } \\
\text { income } \\
\text { growth }\end{array}$} & $\begin{array}{l}\text { Between } \\
\text { groups }\end{array}$ & 19.153 & 3 & 6.384 & 2.021 & .121 & 5.23 & 4.29 & 4.71 & 3.25 \\
\hline & Within groups & 176.884 & 56 & 3.159 & & & & & & \\
\hline & Total & 196.037 & 59 & & & & & & & \\
\hline \multirow{3}{*}{$\begin{array}{l}\text { Market } \\
\text { share } \\
\text { growth }\end{array}$} & $\begin{array}{l}\text { Between } \\
\text { groups }\end{array}$ & 51.778 & 3 & 17.259 & 6.628 & .001 & 5.54 & 3.41 & 5.67 & 4.75 \\
\hline & Within groups & 145.822 & 56 & 2.604 & & & & & & \\
\hline & Total & 197.600 & 59 & & & & & & & \\
\hline \multirow[t]{3}{*}{$\begin{array}{l}\text { Total } \\
\text { revenue } \\
\text { growth }\end{array}$} & $\begin{array}{l}\text { Between } \\
\text { groups }\end{array}$ & 2.321 & 3 & .774 & .692 & .561 & 3.62 & 3.72 & 4.07 & 3.42 \\
\hline & Within groups & 62.572 & 56 & 1.117 & & & & & & \\
\hline & Total & 64.892 & 59 & & & & & & & \\
\hline \multirow{3}{*}{$\begin{array}{l}\text { Overall } \\
\text { performan } \\
\text { ce }\end{array}$} & $\begin{array}{l}\text { Between } \\
\text { groups }\end{array}$ & 54.462 & 3 & 18.154 & 8.435 & .000 & 5.5 & 3.35 & 5.1 & 3.75 \\
\hline & Within groups & 120.521 & 56 & 2.152 & & & & & & \\
\hline & Total & 174.983 & 59 & & & & & & & \\
\hline
\end{tabular}

\section{DISCUSSION}

The strategy-performance link has been examined by a large number of researchers, with conflicting results. Porter's generic strategies are among those most heavily investigated by strategic management scholars. A number of researchers have argued that, in addition to these strategies, firms can also pursue hybrid strategies. These strategies vary from having no strategy, to pursuing aspects of lowcost and differentiation at the same time, to changing strategies over time (Leitner \& Guldenberg, 2010).

The purpose of this research was to explore the existence of generic strategies among a sample of firms in Bahrain and to understand how these strategies affect some performance indicators in this emerging economy. The results of the factor analysis reveal the existence of four strategies: differentiation, hybrid, low-cost, and focused differentiation. Differentiation strategy depends mainly on marketing practices such as developing a broad range of products, innovation in marketing techniques and methods, providing specialty products and services, producing products/services for high-price market segments, utilizing advertising, building a positive reputation within the industry for technological leadership, forecasting existing market growth, fostering innovation and creativity, and partnering with suppliers. Allen \& Helms (2006) note that, for the differentiation strategy, innovation seems to be the most critical factor for success. Fostering innovation and creativity, as well as innovation in marketing technology and methods, were both significant as well. Hybrid strategy included factors related to tight control of overhead cost, providing outstanding customer service, intense supervision of front-line employees, extensive training of marketing personnel, maintaining high inventory levels (for manufacturing organizations) or high staffing levels (for non-manufacturing 
organizations), competitive pricing, refining existing products, minimizing distribution costs (for manufacturing organizations) or service costs (for non-manufacturing organizations), dropping unprofitable customers, and building market share. It is called "hybrid strategy" because it combines certain tactics of low-cost providers and differentiators. Low-cost strategy included factors related to vigorous pursuit of cost reduction, improving operational efficiency, and controlling the quality of products and services. Finally, focused differentiation included two factors related to developing brand or company name identification and targeting a market niche. Because of the low reliability of this variable, it was eliminated from the analysis. The fact that innovation is a major tactic used by differentiators provides support to the findings of Allen \& Helms (2006). Furthermore, the inclusion of quality control in the low-cost strategy is consistent with the findings of Amoako-Gyampah \& Acquaah (2008) in Ghana that quality should be part of both low-cost and differentiation strategies of firms in emerging economies.

Conversely, the factor analysis findings differ from those of Allen \& Helms (2006) in some respects. While this research reported the existence of four factors related to differentiation, low-cost, focused differentiation, and a hybrid strategy, Allen \& Helms (2006) report four somewhat different factors: low-cost leadership, differentiation, focused cost, and focused differentiation. Our findings partially support the findings of Dess \& Davies (1984), who report the existence of three sets of strategic tactics: low-cost, differentiation, and hybrid strategies.

A six-step cluster analysis was conducted using the three variables of low-cost, differentiation, and hybrid strategy as the cluster variate. Four clusters were obtained. The first cluster $(\mathrm{n}=22)$ represented differentiators. These were companies with the highest mean with respect to differentiation and hybrid strategies. Cluster $3(n=9)$ included low-cost providers, i.e., firms that pursue cost-reduction techniques. The means of differentiation and hybrid strategies for this group were slightly lower than those of differentiators. Cluster $4(n=12)$ included hybrids. The mean of this cluster was higher than that of cluster 2 with respect to differentiation and hybrid strategies, but they had the same scores with respect to low cost. Finally, cluster $2(n=17)$ included stuck-in-the-middle firms. The scores of this cluster were the lowest for all three variables.

A number of findings were obtained from the cluster analysis. First, the relatively close scores of differentiation and low-cost practices for both low-cost and differentiation clusters means that even low-cost providers undertake some practices related to differentiation, and firms seeking differentiation also pursue some practices related to low cost. This is consistent with Porter's notion that low-cost providers should have some basis for differentiation in order to be able to compete with differentiators, and the reverse is also true. Karnani (1984) also notes that a firm cannot pursue one strategy at the expense of the other. Hybrids also had high scores for differentiation, while stuck-inthe-middle had low scores on differentiation practices. This finding reflects the fact that companies pursuing differentiation, low-cost, or hybrid strategies tend to emphasize marketing-related practices as a way to differentiate their products. In economies such as Bahrain, where consumer purchasing power is generally high and a large number of imported products compete with locally produced goods and services, differentiation based on branding, specialty products, advertising, and other marketing practices is a must.

Second, the cluster analysis distinguishes between the two strategies of hybrids and stuck-in-themiddle firms. Hybrids have higher scores than stuck-in-the-middle for differentiation, low-cost, and hybrid strategies. This means that the two strategies reflect two different strategic stances. While hybrids deliberately pursue different practices to achieve a competitive advantage, stuck-in-the-middle companies fail in these efforts. This provides support to Leitner \& Guldenberg (2010), who argue that stuck-in-the-middle firms do not constitute a homogeneous_group; there are companies that deliberately combine traditional low-cost production and differentiation, firms that change their strategy, and those that have no strategy.

Third, ANOVA revealed the existence of significant differences among the four clusters with respect to three performance indicators: total assets growth, market share growth, and overall performance. Hybrids had the highest score for total assets growth, low-cost providers had the highest score for market share growth, and differentiators had the highest score for overall performance. These findings mean that the specific strategy-performance link will depend on the type of performance measure 
used. For companies pursuing a low-cost strategy, a higher market share is a plausible goal to pursue in order to achieve scale economies. Conversely, differentiators might be able to achieve better overall performance because of their emphasis on better satisfaction of the needs of their target market. Finally, hybrids had the highest performance related to total assets growth. This finding provides support for the study of Leitner \& Guldenberg (2010), who report higher growth rates for small- to medium-sized firms pursuing a hybrid strategy. It also supports the findings of Parnell (1997), who reports that balancers (who do not adopt one pure strategy) maintain higher return on assets measured through financial indicators. It contradicts the findings of Dess \& Davis (1984), however. They report that a focused low-cost strategy provides the highest total assets growth. Hybrids undertake a combination of low-cost and differentiation strategic tactics; they address customer needs better; they may be more difficult to imitate; and they may generate a more flexible, wider view than firms pursuing pure strategies (O'Regan et al., 2011). Thus, hybrids may appear as better performers under certain circumstances, such as specific demand conditions that do not support differentiation beyond a standard readily achievable by competitors; new organizational structures; information technology (Campbell-Hunt, 2000); modern production technology; and management practices that allow firms to simultaneously reduce costs and differentiate products (Leitner \& Guldenberg, 2010). The low scores for all performance indicators for stuck-in-the-middle firms also provide support for the findings of Leitner \& Guldenberg (2010) for firms with no coherent strategy.

The above findings shed some light on the complexity of examining the strategy-performance link. This complexity is reflected in the inconsistency in research findings concerning this link. It stems from having a large number of performance determinants with generic strategies constituting only one single determinant. These determinants include environmental and firm determinants. Industry structure is also a major environmental determinant. Variables such as cost economies, scope economies, and industry advertising expenditures affect various organizational performance indicators even though the effect of strategy might be more pronounced (Spanos et al., 2004). In addition to environmental variables, firm determinants such as resources, competencies (Desarbo et al., 2005), and goals (Park \& Helms, 1992) also affect performance measures. The analysis more complicated given the existence of different performance measures and the fact that various strategies affect these measures in different ways.

\section{Research Implications}

This research has a number of implications for both academicians and practitioners. Academically, it attempts to examine the strategy-performance link in an emerging economy. In such economies, companies are faced with high environmental dynamism and intense competition, forcing them to pursue multiple strategic postures at the same time. The finding that companies pursuing differentiation perform better than other firms with respect to overall performance indicates the importance of factors such as innovation and marketing in emerging markets, where competition is becoming more intense than before. Competition from firms based in countries with lower cost conditions means that differentiation may be the only route to achieve performance advantages (Pertusa-Ortega et al., 2009). Firms pursuing a hybrid strategy emphasizing both cost and differentiation performed better, with respect to total assets growth, than firms pursuing other strategies. This means that flexibility might be a major competitive weapon for firms competing in emerging economies.

From a practical viewpoint, the research offers guidelines to firms working in emerging economies such as Bahrain. These companies will have to pursue a differentiation strategy that is based on quality, innovation, specialty goods and services, training of front-line employees, a strong reputation, and advertising. This means that they will have to seek a clear understanding of customer needs in these economies so as to provide them with need-satisfying products. Marketing research is a major tool that can be used to help marketing decisions in such economies. The challenge is even higher for multinationals working in emerging economies. MNCs will have to examine the extent of adaptation required in such economies. 


\section{Limitations and Suggestions for Future Research}

The major limitation of this research relates to the small size of the sample. Future research should utilize larger samples. A number of variables can be examined that moderate the relationship between the generic strategy type and performance. Possible moderators include type of industry, competitive threats, environmental complexity, and dynamism. The use of a cross-sectional design is also a major limitation of this research. O'Farrell et al. (1993) note that there is no substitute for longitudinal research to explore the dynamic causal connections and performance implications of the relationships between competencies, competitive advantage, generic strategy, and environment. Longitudinal research is even more important in emerging economies in order to take account of dynamic changes in the institutional environment (Hoskisson et al., 2000).

The use of cluster analysis is another limitation. Its primary weakness is that it concentrates on similarities within clusters (groups) and does not account for strategy differences within groups (O'Regan et al., 2011). To overcome the problem of using a multi-sectoral sample, subjective performance measures were used. These are sometimes biased. Different results could be obtained by using financial measures, as well as non-financial measures such as loyalty and satisfaction. The use of a balanced score card is recommended by some scholars (Jusoh \& Parnell, 2008).

Finally, because of the exploratory nature of this research, the effect of some moderating variables was not examined. Variables such as industry type, firm competencies, degree of market concentration, and type of customers may moderate the effect of strategy on performance, leading to more complex models of performance. 


\section{REFERENCES}

Allen, R.S. \& Helms, M.M. (2006), Linking strategic practices and organizational performance to Porter's generic strategies, Business Process Management Journal, 12 No. 4, p. 433.

Amoako-Gyampah, K. \& Acquaah, M. (2008), Manufacturing strategy, competitive strategy and firm performance: an empirical study in a developing economy environment, International Journal of Production Economics, 111 , pp. 575-92.

Baack, D.W. \& Boggs, D.J. (2008), The difficulties in using a cost leadership strategy in emerging markets, International Journal of Emerging Markets, 3 No. 2, pp. 125-39.

Burns, R. \& Burns, R. (2008), Business Research Methods and Statistics Using SPSS, Sage, Publications, Thousand Oaks, CA.

Campbell-Hunt, C.C. (2000), What have we learned about generic competitive strategy? A metaanalysis, Strategic Management Journal, 21, pp. 27-154.

Chan, R.Y. \& Wong, Y.H. (1999), Bank generic strategies: does Porter's theory apply in an international banking center?, International Business Review, 8 , pp. 561-90.

Davis, H. \& Walters, P. (2004), Emerging patterns of strategy, environment and performance in a transition economy, Strategic Management Journal, 25, pp. 347-64.

Dawes, J. \& Sharp, B. (1996), Independent empirical support for Porter's generic marketing strategies? A re-analysis using correspondence analysis, Journal of Empirical Generalisations in Marketing Science, 1, pp. 36-52.

Desarbo, W., Di Benedetto, C.A., Song, M. \& Sinha, I. (2005), Revisiting the Miles and Snow strategic framework: uncovering interrelationships between strategic types, capabilities, environmental uncertainty, and firm performance, Strategic Management Journal, 26, pp. 47-74.

Dess, G. \& Davis, P.S. (1984), Porter's (1980) generic strategies as determinants of strategic group membership and organizational performance, The Academy of Management Journal, 27, No. 3, pp. 467-88.

Hair, J.S., Anderson, R.E., Tetham, R.L. \& Black, W.C. (1998), Multivariate Data Analysis, 5th ed., Prentice-Hall, Upper Saddle River, NJ.

Hoskisson, R.E., Eden, L., Lau, C.M. \& Wright, M. (2000), Strategy in emerging economies, Academy of Management Journal, 43 No. 3, pp. 249-67.

Jusoh, R. \& Parnell, J.A. (2008), Competitive strategy and performance measurement in the Malaysian context: an exploratory study, Management Decision, 46, No. 1, pp. 5-31.

Karnani, A. (1984), Generic competitive strategies: an analytical approach, Strategic Management Journal, 5 No. 4, pp. 367-80.

Kim, E., Nam, D. \& Stimpert, J.L. (2003), The applicability of Porter's generic strategies in the digital age: assumptions, conjectures, and suggestions, Journal of Management, 30 No. 5, pp. 569-89.

Kim, L. \& Lim, Y. (1988), Environment, generic strategies, and performance in a rapidly developing country: a taxonomic approach, The Academy of Management Journal, 31 No. 4, pp. 802-27.

Kumar, K. \& Subramanian, R. (1998), Porter strategic types: differences in internal processes and their impact on performance, Journal of Applied Business Research, 14 No. 1, pp. 107-24.

Leitner, K.L. \& Guldenberg ,S. (2010), Generic strategies and firm performance in SMEs: a longitudinal study of Austrian SMEs, Small Business Economics, 35, pp. 169-89.

Li, C.B. \& Li, J.J. (2008), Achieving superior financial performance in China: differentiation, cost leadership, or both?, Journal of International Marketing, 16 No. 3, pp. 1-22.

Li, J.J., Zhou, K.Z. \& Shao, A.T. (2009), Competitive position, managerial ties, and profitability of foreign firms in China: an interactive perspective, Journal of International Business Studies, 40, pp. 339-52. 
Lumpkin, G.T. \& Dess, G.G. (2006), The effect of 'simplicity' on the strategy-performance relationship: a note, Journal of Management Studies, 43, pp. 1583-604.

Masokowski, E. (1993), A resource-based perspective on the dynamic strategy-performance relationship: an empirical examination of the focus and differentiation strategies in entrepreneurial firms, Journal of Management, 19 No. 4, pp. 819-39.

Murray, A. (1988), Contingency view of Porter's generic strategies, The Academy of Management International Review, 13 No. 3, pp. 390-400.

Myers , L.M., Gamst, G. and Guarino, A.J. (2006), Applied Multivariate Research: Design and Interpretation, Sage Publications, Thousand Oaks, CA.

Norusis, M.J. (1990), SPSS: Advanced Statistics User's Guide, SPSS, Chicago, IL.

O'Farrell, P.N., Hitchens, D.M. \& Moffat, L.A.R. (1993), The competitive advantage of business service firms: a matched pairs analysis of the relationship between generic strategy and performance, The Service Industry Journal, 13 No. 1, pp. 40-64.

Olson, E.M., Slater, S.F. \& Hult, G.T.M. (2005), The performance implications of business strategy, marketing organization structure, and strategic behavior, Journal of Marketing, 69 No. 3, pp. 49-65.

O'Regan, N., Kluth, C. \& Parnell, J. (2011), The demise of strategic groups as an influence on firm performance: lessons from the UK plastics industry, Strategic Change, 20, pp. 111-26.

Parker, B. \& Helms, M.M. (1992), Generic strategies and firm performance in a declining industry, Management International Review, 32 No. 1, pp. 23-39.

Parnell, J.A. (1997), New evidence in the generic strategy and business performance debate: a research note, British Journal of Management, 8, pp. 175-81.

Parnell, J.A. (2006), Generic strategies after two decades: a reconceptualization of competitive strategy, Management Decision, 44 No. 8, pp. 1139-54.

Parnell, J.A. (2010), Strategic clarity, business strategy and performance, Journal of Strategy and Management, 4, pp. 304-24.

Pertusa-Ortega, E.M., Molina-Azorín, J.F. \& Claver-Cortés, E. (2009), Competitive strategies and firm performance: a comparative analysis of pure, hybrid and 'stuck-in-the-middle' strategies in Spanish firms, British Journal of Management, 20, pp. 508-23.

Porter, M. (1980), Competitive Strategy, Free Press, New York, NY.

Porter, M. (1985), Competitive Advantage: Creating \& Sustaining Superior Performance, Free Press, and New York, NY.

Powers, T.L. \& Hahn, W. (2004), Critical competitive methods, generic strategies, and firm performance, International Journal of Bank Marketing, 22 No. 1, pp. 43-64.

Spanos, Y., Zaralis, G. \& Lioukas, S. (2004), Strategy and industry effects on profitability: evidence from Greece, Strategic Management Journal, 25, pp. 139-65.

University of Texas, Detecting Outliers, available at www.utexas.edu/courses/schwab/sw388r7/SolvingProblems/DetectingOutliers.ppt, retrieved 14 January 2013.

Walker, O.C. \& Reukert, R.W. (1987), Marketing's role in the implementation of business strategies: a critical review and conceptual framework, Journal of Marketing, 51, pp. 15-31.

White, R.E. (1986), Generic business strategies, organizational context and performance: an empirical investigation, Strategic Management Journal, 7, pp. 217-31.

Wright, M., Filatotchev, I., Hoskisson, R.E. \& Peng, M.W. (2005), Strategy research in emerging economies: challenging the conventional wisdom, Journal of Management Studies, 42, pp. 1-33. 